\title{
Population structure, linkage disequilibrium and association mapping for cotton leaf curl disease incidence in cotton (Gossypium hirsutum L.)
}

Muhammad Saeed ( $\sim$ saeed242@hotmail.com )

Government College University https://orcid.org/0000-0002-7125-7394

Anam Tariq

Government College University Faisalabad

Shagufta Perveen

Government College University Faisalabad

Amina Altaf

Government College University Faisalabad

Sumera Ashfaq

Government College University Faisalabad

Muhammad Riaz

Ayub Agricultural Research Institute

Xianliang Song

Shandong Agricultural University

Xuezhen Sun

Shandong Agricultural University

Tianzhen Zhang

Zhejiang University

\section{Research article}

Keywords: Cotton leaf curl virus, Disease, General linear model, Linkage disequilibrium, Population structure, Simple sequence repeats

Posted Date: November 25th, 2019

DOI: https://doi.org/10.21203/rs.2.17562/v1

License: (c) (1) This work is licensed under a Creative Commons Attribution 4.0 International License.

Read Full License 


\section{Abstract}

Background: Cotton ( Gossypium hirsutum L.) production is adversely affected by many biotic and abiotic factors. Among the biotic factors, cotton leaf curl disease (CLCUD), caused by a begomovirus, is the most damaging. An association mapping approach was used to find out population structure and linkage disequilibrium in cotton germplasm; and simple sequence repeat (SSR) markers associated with CLCuD infestation and seed cotton yield per plant (SCY).

Results: Data was recorded for percent disease index (PDI) and SCY of 30 diverse cotton cultivars. Out of one thousand SSR markers used for polymorphism screening of plant material, 125 were found polymorphic and used for genotyping of 30 cultivars. STRUCTURE 2.0 software identified three subpopulations in plant material. Linkage disequilibrium (LD) analysis showed that at $P<0.05,270 / 7750$ marker pairs (3.48\%) displayed significant pair-wise LD and values for correlation between alleles at two loci ( $r 2$ ) and disequilibrium coefficient ( $D \otimes$ ) were $>0.05$ and $>0.33$, respectively, which were stringent enough for identification of valid marker-trait associations. Three markers (BNL1421, BNL946, NAU2336) were associated with PDI and five markers (NAU3100, NAU3860, NAU2419, NAU3011, NAU4565) were associated with SCY under both GLM (general linear model) and MLM (mixed linear model) analyses.

Conclusion: Marker BNL1421 (with phenotypic variance explained ( R 2 ) and heritability values of $26.45 \%$ and 0.90 , respectively) would be a valuable candidate in marker-assisted selection (MAS) to screen CLCuD susceptible cotton genotypes. Findings of this study will help in understanding genetics of CLCuD infestation and designing future molecular breeding programmes to control this disease. Keywords: Cotton leaf curl virus, Disease, General linear model, Linkage disequilibrium, Population structure, Simple sequence repeats

\section{Background}

Cotton (Gossypium hirsutum L.) is the most important natural textile fiber worldwide and the world's sixth largest source of vegetable oil. China, India, USA and Pakistan are largest cotton producing countries in the world [1]. Cotton seeds are important source of food [2]. Cotton is known as the cash crop due to its high economic value. Cotton is considered as the life line of economy of Pakistan. The share of cotton in GDP of Pakistan is $0.8 \%$ [3]. It plays role as backbone of Pakistan's economy by producing the lint, which is used in textile industry [4].

Cotton belongs to genus Gossypium and family Malvaceae. The family Malvaceae contains 90 genera. The genus Gossypium includes shrubs and saplings [5-6]. The genus Gossypium has 45 diploid and 5 allotetraploid species that occur in semiarid and arid areas of Africa, Central and South America, Galapagos, Indian subcontinent, Australia, Arabia, and Hawaii [7]. Currently cotton has only 4 cultivated species, out of which two are tetraploid species including G. hirsutum L. and G. barbadense L. The other species are diploid such as $G$. arboreum $L$., and $G$. herbaceum $L$. Tetraploid species were formed by merging of two diploid genomes, out of which one genome has similarity with A-genome diploids found 
in old world while other genome is similar to the D-genome diploids of new world. Tetraploid species evolved by hybridization between an African A genome and an American D genome about 1-2 million years ago $[8,9]$. Diploid species are divided into eight genomic groups A-G and K [10]. Spinable fiber is the product of A genome species [11]. World's cotton production is largely based on Gossypium hirsutum and Gossypium barbadense [12]. Gossypium hirsutum, also known as Upland and Mexican cotton, represents $90 \%$ of global fiber production. It produces longer, stronger and finer fiber [13]. Gossypium barbadense, also known as Pima cotton, involves in $8 \%$ global cotton production. It is valued for its higher quality fiber [14]. Gossypium arboreum (Tree cotton) and Gossypium herbaceum (Levant cotton) contribute less than $2 \%$ of global cotton production [15].

World's agriculture production is adversely affected by diseases caused by viruses and unfavorable climatic conditions [16]. Cotton production is threatened by many biotic and abiotic stresses. Among biotic stresses, cotton leaf curl disease (CLCUD) is most damaging. CLCuD is considered as the major threat to cotton production in Pakistan [17]. CLCuD restricts the cotton production by $20 \%-30 \%$ annually in Pakistan which depends on the severity of the disease $[18,19]$. Millions of cotton bales have affected by this disease and country faced economic difficulties. It is estimated that Pakistan economy suffered a loss of 75 million rupees during last ten years due to CLCUD [20]. CLCUD is transmitted by the whitefly Bemisia tabaci [21]. This disease is caused by a begomovirus, belonged to the family Geminiviridae. Geminiviruses infect both monocotyledonous and dicotyledonous plants. Cotton leaf curl virus has a wide range of alternative hosts including okra, tomato, potato, Chinese rose, tobacco, lehli and dhatura [22].

Geminiviruses are single stranded circular DNA viruses. The genome of these viruses consists of 25005200 bases. The family Geminiviridae is divided into nine genera on the basis of arrangement of genome and vector. Several insects are involved in the transmission of these viruses such as aphids, leafhoppers, treehoppers and whiteflies. Whiteflies are involved in the transmission of begomoviruses [23]. The largest genus of family Geminiviridae is begomovirus. More than 320 species are present in this genus. Dicotyledonous plants are infected by begomoviruses [21]. Production of many crops including cotton is reduced on a large scale by begomoviruses in temperate, tropical and sub-tropical areas. All members of family Geminiviridae are monopartite except begomoviuses [23]. Begomoviruses are of two types including monopartite and bipartite begomoviruses. Most of begomoviruses genome contains two types of components. One is known as DNA A and other is known as DNA B. These begomoviruses are known as bipartite viruses. The size of both components of genome is same. Each component of genome is consisting of about 2600 nucleotides. Only DNA A is present in monopartite begomoviruses [21]. Monopartite begomoviruses are responsible for $\operatorname{CLCuD}[24,25]$. The DNA A of bipartite genome contains 6 genes out of which $V 1$ and $V 2$ genes are present on sense strand while other 4 genes are present on antisense strand such as $C 1, C 2, C 3$ and $C 4$ genes. These genes encode different proteins. For example, replication-initiation protein (Rep) is encoded by $C 1$ gene while $C 2$ gene encodes transcriptional activator protein. Replication enhancer protein is encoded by $C 3$ gene. $C 4$ encodes protein that is necessary for movement of virus. This protein determines the severity of disease and range of host [26]. Two types of satellites are associated with begomoviruses. These satellites are known as alphasatellites and 
betasatellites [24]. The size of alphasatellites is about 1.4kb. Allphasatellites do not take part in the determination of disease symptoms [27]. The level of viral DNA in infected plants is suppressed by alphasatellites [28]. The replication of helper virus is enhanced by betasatellites. Betasatellites consist of about 1350 nucleotides. These are small and non-circular ssDNA satellites which are linked with majority of monopartite begomoviruses. The protein $(\beta C 1)$ which determines the symptoms of disease is also encoded by betasatellites. The severity of disease is determined by the betasatellites [24]. Disease severity is positively correlated with vrisue/satellite DNA thus more virus/satellite results into more disease severity [17].

CLCuD first appeared in Nigeria in 1916. But in Pakistan, the cotton plants were first attacked by this disease in 1967 at Tiba Sultan Pur near Multan district. Its first epidemic in Pakistan appeared during 1992-93 [29]. CLCuD has specific symptoms such as growth stunting, visibility of thickened veins, leaf darkening, and leaf enations may be one or more on the underside side of leaf. Enation is a leaf like small outgrowth of plant tissue that is caused by a virus infection [24]. CLCuD caused two types of thickening of veins on cotton plants; i) major vein's thickening ii) minor vein thickening. Leaf margins become thick at the initial stage of disease [30]. Seriously infected plant has shortened internodal length that results into stunted growth of the plant [24,31]. CLCuD adversely affects fiber quality. It also reduces seed weight, number of monopodial and sympodial branches [32]. Its susceptible plants have darker color than normal plants due to the proliferation of chlorophyll deposited tissues [33].

Different strategies are used to compete with the problem of CLCuD. But the best option is to use the resistant cultivar. Molecular mapping approach can help to identify the genomic regions of cotton associated with CLCuD resistance. Association mapping is a recent molecular mapping approach which has great resolution. Association mapping (AM), also known as linkage disequilibrium (LD)-based mapping, is used to identify genomic regions associated with phenotypic variations [34]. This technique is used to determine marker-trait associations with the help of genome-wide distributed genes and markers and to study the architecture of the trait. This technique is appropriate for both synthetic and natural populations [35]. AM is a technique that is used to analyze a large number of polymorphisms to assess the QTL effect. It does not require generation of segregating population and a large number of progeny, due to which it is more preferable than linkage analysis (LA). Association mapping can increase mapping resolution. It decreases the research time and greater number of alleles is identified [36]. In the present project, an association mapping approach was used to identify simple sequence repeat (SSR) markers associated with CLCuD resistance in cotton.

\section{Results}

\section{Phenotypic variation}

Great differences were observed among the cultivars for PDI and SCY as revealed from the ANOVA of combined data of two years (Table 2). Performance of genotypes with regard to PDI and SCY differed significantly during 2015 and 2016. MS-39 did not show any symptoms of CLCuD during both 2015 and 
2016, whereas, MNH-636 showed higher values of PDI during 2015 and 2016. CLCuD infestation is very complex and fluctuations are observed at a single site with regard to same cotton genotype. This was reflected in significant differences of PDI within blocks. The minimum value for PDI during 2015 and 2016 was 0 while the maximum value for PDI during 2015 and 2016 was 25.89 and 28.34, respectively. The minimum value for SCY during 2015 and 2016 was $30.67 \mathrm{~g}$ and $102 \mathrm{~g}$, respectively. The maximum value of SCY for 2015 and 2016 was $129.65 \mathrm{~g}$ and $324.13 \mathrm{~g}$, respectively.

\section{Genotyping, STRUCTURE and LD analyses}

The plant material was surveyed for polymorphism with 1000 SSR markers. One hundred and twenty five markers were found polymorphic. Out of 125 markers, 111 markers yielded 2 alleles, 12 markers yielded 3 alleles, and 2 markers yielded 4 alleles. Subsequent STRUCTURE and LD analyses were performed with the help of genotypic data of these 125 polymorphic markers. STRUCTURE analysis identified three subpopulations in the plant material. Overall proportion of membership of the plant material in each of the 3 sub-populations was $0.57,0.16$, and 0.27 , respectively.

Sub-population 1 included 19 cultivars namely CIM-1100, VH-148, Stoneville, SLS-1, MS-39, MNH636, MNH-554, MNH-552, LSS, FH-901, FH-900, FH-682, FH-1000, FH-113, IR-NIAB-824, CIM-499, $\mathrm{CIM}-496, \mathrm{BH}-118$, and B557. Sub-population 2 included 3 cultivars namely $\mathrm{CIM}-506, \mathrm{CIM}-482$, and $\mathrm{MNH}-814$. Sub-population 3 included 5 cultivars namely CIM-448, CIM-446, CIM-109, BS-1, and CIM473. Three cultivars namely MS-40, 4-F, and 268-F were admixtures.

Out of total 7750 marker pair combinations, 270 (3.48\%), 86 (1.11\%), and $29(0.37 \%)$ marker pairs exhibited LD at $P<0.05, P<0.01$, and $P<0.001$, respectively. List of marker pairs which exhibited higher $\mathrm{LD}$ is given in Table 3. A non-random linkage between loci located on different chromosomes was observed. At $P<0.05$, values for correlation between alleles at two loci $\left(r^{2}\right)$ and disequilibrium coefficient $(D Q)$ were $>0.05$ and $>0.33$, respectively. These values were stringent enough for identification of valid marker-trait associations. Therefore, analysis for marker-trait associations assessment was performed.

\section{Marker-trait associations}

There were 8 significant $(P \leq 0.05)$ marker-trait associations identified by GLM analysis (Table 4). Phenotypic variance explained values $\left(R^{2}\right)$ for these associations ranged from $11.13 \%$ to $26.91 \%$. Three markers were associated with PDI out of which two are in 2016 data set and one is from 2016 data set. These markers were BNL1421 (A13-Chr13), BNL946 (D10-Chr20), and NAU2336 (D2-Chr14). Five markers were found to be associated with SCY in the data set of 2016. These markers were NAU3100 (D9-Chr23), NAU3860 (A12-Chr12), NAU2419 (A1-Chr1), NAU3011 (D13-Chr18), and NAU4565. These marker-trait associations were also confirmed by MLM (mixed linear model) analysis (Table 5). MLM analysis showed that marker BNL1421 (A13-Chr13) associated with PDI in 2015 data had higher heritability value. 
This marker had greater genetic variance component (21.43) in the total variance (23.75). This marker would be a good candidate for screening CLCuD susceptible cotton genotypes.

\section{Discussion}

\section{CLCuD susceptibility is a quantitative trati}

CLCuD is the major cause of huge loss to world cotton production, especially in Pakistan, India, and China [37]. In Pakistan, there is considerable reduction in cotton crop area due to non-availability of CLCuD resistant elite cotton cultivars and cotton farmers were forced to cultivate alternative crops for sustainable earnings from their agricultural lands [3]. Conventional breeding programmes in different countries were successful to develop CLCuD resistant cotton varieties, but all these varieties were with very low SCY potential [38]. These cotton varieties were out of farmers' production scheme within few years after their approval as these varieties could not meet farmers' economic concerns. For sustainable cotton production, it is direly needed that cotton cultivars having CLCuD resistance with higher SCY potential be developed. For combining CLCuD resistance and high SCY potential in a cotton variety is a challenging task. This needs a thorough knowledge and information about genetic potential of cotton genotype for CLCuD resistance as well as its genetic architecture for SCY potential.

Molecular mapping approaches help to tag genomic regions associated with traits of interest $[34,36,39,40]$. Identified markers through these mapping approaches can be incorporated in to markerassisted selection (MAS) programmes to pyramid desirable alleles in a single crop cultivar. In this study, CLCuD susceptibility loci were found located on chromosomes 13 (BNL1421), 14 (NAU2336), and 20 (BNL946). This study showed that CLCuD susceptibility is not a simple Mendelian character controlled by one gene. More than one loci are involved in CLCuD susceptibility. These loci are scattered on different chromosomes. Both A and D genomes contained CLCuD susceptibility loci.

\section{Marker-assisted selection for developing CLCuD tolerant genotypes}

In the past, there was paucity of DNA markers associated with CLCuD susceptibility/tolerance. Being a complex genetic character, development of CLCuD tolerant genotypes through conventional breeding approach is not a feasible option as it is time consuming and selection of elite genotypes is cumbersome through this approach. Marker-assisted selection (MAS) and subsequent genomics-assisted breeding is the way forward. Identified markers associated with CLCuD susceptibility, especially marker BNL1421, which had higher heritability value of 0.90 , would be suitable marker to screen out CLCuD susceptible cotton genotypes. This locus would be further characterized to understand genetics of CLCuD susceptibility.

\section{Conclusions}


CLCuD is affecting cotton production in many countries of the world. This study showed that cotton genotypes had considerable differences and diversity with regard to CLCuD tolerance. MS-39, cotton cultivar showing highest tolerance to CLCuD, needs to be genetically characterized to understand CLCuD tolerance mechanism in minute details. Similarly, genetic characterization of $\mathrm{MNH}-636$, cotton cultivar with highest susceptibility to CLCuD, would also be helpful in designing genomics-assisted breeding (GAB) strategy to develop elite cotton cultivars with CLCuD tolerance. Fine mapping of identified markers associated with PDI would lead to identification of putative genes/alleles involved in CLCuD susceptibility/tolerance. Findings of this study showed that more than one loci were involved in CLCUD susceptibility and GAB is the most suitable strategy to develop elite CLCUD tolerant cotton genotypes with sustained SCY potential and conventional breeding efforts are inadequate to meet this challenge.

\section{Material And Methods}

\section{Plant material}

Plant material consisted of thirty cultivars of cotton (Gossypium hirsutum L.). List of these cultivars, including their original sources, is given in Table 1. All these were commercial cultivars originated from different cotton research centers of Pakistan and USA. These cotton cultivars were part of cotton germplasm maintained at Cotton Research Station, Ayub Agricultural Research Institute, Faisalabad, Pakistan (CRS-AARI, FSD) (https://aari.punjab.gov.pk/crs_faisalabad). CRS-AARI, FSD routinely acquires cotton germplasm from national and international cotton research institutes to fulfill its objective of "expansion of gene pool" and maintains this cotton germplasm in a very systematic and planned manner with complete record of source and origin. It is fully authorized and had license for this cotton germplasm collection and maintenance. Field experimentation of this study was conducted at CRS-AARI, FSD. Cotton cultivars were selected on the basis of their diversity for CLCuD susceptibility/tolerance during 20132015. Plant material was sown at research field of CRS-AARI, FSD during 2015-2016. The seeds of thirty varieties were sown on 15-04-2015 and 15-04-2016. The cultivars were sown in randomized complete block design with three replications having $75 \mathrm{~cm}$ row to row and $45 \mathrm{~cm}$ plant to plant distance. Standard agronomic practices were followed for the cultivation of cultivars.

\section{Phenotyping of plant material}

CLCuD infestation scoring of thirty cultivars was done in terms of percent disease index (PDI). CLCuD scoring was done on 15-9-2015 and 18-09-2016. Cotton cultivars were scored for CLCuD infestation according to the 6-scale symptoms severity given by Akhtar et al. (2010) [41].

Percent disease index was calculated by following formula: 
Percent Disease Index

$\frac{\text { By adding all disease scoring stages in selected individual plant }}{\text { Total number of plants }} X 100 / 6$

At maturity, the data for seed cotton yield per plant (SCY) was recorded. SCY was measured in grams (g) with laboratory measuring balance.

\section{SSR genotyping}

Plant material was screened for polymorphism using 1000 simple sequence repeat (SSR) markers. Ninety-two SSR markers were found polymorphic. Genomic DNA was extracted by using $4-5$ young, fully expanded leaves. Leaves were stored at $-80^{\circ} \mathrm{C}$. DNA was extracted by using DNA extraction Aidlab DNA mini kit (Cat \#: DNA15, Lot: 261525AX). The DNA integrity was checked by electrophoresis on $1 \%$ agarose gel and quantified by Nanodrop 2000. The DNA amplification was performed by using standard PCR procedures described by Zhang et al. (2000) [42]. The DNA amplification of thirty commercial cultivars was performed by SuperCycler thermal cycler (Model: SC300G, Kyratec limited, Australia). This amplification was carried out with the help of Bioron Taq Master Mix, Bioron DFS-Taq DNA Polymerase, Bioron set of 4 dNTPs and Bioron 100 bp plus DNA ladder ready-to-use. Ninety-two polymorphic primers were used for amplification. DNA bands of amplification product were developed with silver staining and recorded with SX-image system. SSR markers were scored on their base pair sizes. Missing data was indicated by " -9 " and "?" according to the software requirements.

\section{STRUCTRE analysis}

The pattern of population/genetic structure in thirty cultivars was assessed by using software package STRUCTURE [43]. It is a model-based clustering method.

\section{Analysis of marker-trait associations}

Marker-trait associations were assessed by GLM (general linear model) association test incorporating genotypic and phenotypic data; and $Q$ (structure relatedness) matrices into TASSEL 2.1 software [44]. TASSEL stands for Trait Analysis for aSSociation, Evolution and Linkage.

\section{Abbreviations}

AM: Association mapping; CLCUD: Cotton leaf curl disease; CoV: Coefficient of variation; GLM: General linear model; $L A$ : Linkage analysis; $L D$ : Linkage disequilibrium; $M L M$ : Mixed linear model; $P D I$ : Percent disease index; SCY: Seed cotton yield per plant 


\section{Declarations}

\section{Authors' contributions}

MS, SS, XS conceived and designed the experiments. AT, AA and SA performed the experiments. MS, AT, SP and MR analyzed the data. MS, AT, SP, MR and SS wrote the paper. XS and TZ edited the paper. All authors have read and approved the manuscript.

Funding This study was supported by the grants "System of Modern Agriculture Industrial Technology of Shandong province (SDAIT-07-011-02, SDAIT-03-03, SDAIT-03-05)“, "Agriculture Seed Project of Shandong province (2014 cotton variety development)", and "Open Project number 2014 KF01 of the State Key Laboratory of Crop Biology, Shandong Agricultural University, Shandong, China”. These grants were won by XS, SS, and MS respectively. MS, SS, XS conceived and designed the experiments; MS, SS wrote the paper. XS edited the paper.

\section{Availability of data and materials}

Not applicable

\section{Ethics approval}

Not applicable.

\section{Consent for publication}

Not applicable.

\section{Competing interests}

Authors declare that there are no competing interests.

\section{References}

1. Dohlman E, Johnson J, MacDonald S, Meyer L, Soley G. The world and United States cotton outlook. USDA, February 22, 2019.

2. De-Sousa CC, De-Figueirêdo LC, Arrais MDGM, dos santos Valent SE. Genetic map of cotton with molecular markers. Am J Plant Sci. 2015;6(2):289-297.

3. Anonymous. Economic Survey Pakistan 2018-2019. Finance Division, Government of Pakistan, Islamabad. 2019;pp. 16. 
4. Imran M, Shakeel A, Azhar FM, Farooq J, Saleem MF, Saeed A, Nazeer W, Riaz M, Naeem M, Javaid A. Combining ability analysis for within-boll yield components in upland cotton (Gossypium hirsutum L.). Genet Mol Res. 2012;11(3):2790-2800.

5. Judd WS, Campbell CS, Kellogg EA, Stevens PF, Donoghu MJ. Sistemática Vegetal-Um Enfoque Filogenético. Artmed Porto Alegre. 2009.

6. Souza VC, Lorenzi H, Neto ACR. Botânica Sistemática-guia ilustrado para a identificação de famílias de Fanerógamas nativas e exóticas do Brasil em APG II. Nova Odessa. 2008.

7. Kalivas A, Xanthopoulos F, Kehagia O, Tsaftaris AS. Agronomic characterization, genetic diversity and association analysis of cotton cultivars using simple sequence repeat molecular markers. Genet Mol Res. 2011;10(1):208-217.

8. Li F, Fan G, Lu C, Xiao G, Zou C, Kohel RJ, Ma Z, Shang H, Ma X, Wu J, Liang X. Genome sequence of cultivated Upland cotton (Gossypium hirsutum TM-1) provides insights into genome evolution. Nat Biotechnol. 2015;33:524-530.

9. Liu X, Zhao B, Zheng HJ, Hu Y, Lu G, Yang CQ, Chen JD, Chen JJ, Chen DY, Zhang L et al. Gossypium barbadense genome sequence provides insight into the evolution of extra-long staple fiber and specialized metabolites. Sci Rep. 2015;5:14139.

10. Wendel JF, Cronn RC. Polyploidy and the evolutionary history of cotton. Adv Agron. 2003;78:139186.

11. Applequist WL, Cronn R, Wendel JF. Comparative development of fiber in wild and cultivated cotton. Evol Dev. 2001;3(1):3-17.

12. Lin ZX, He D, Zhang XL, Nie Y, Guo X, Feng C, Stewart JM. Linkage map construction and mapping QTL for cotton fibre quality using SRAP, SSR and RAPD. Plant Breed. 2005;124(2):180-187.

13. Thompson AL, Pauli D, Tomasi P, Yurchenko O, Jenks MA, Dyer JM, Gore MA. Chemical variation for fiber cuticular wax levels in upland cotton (Gossypium hirsutum L.) evaluated under contrasting irrigation regimes. Ind Crop Prod. 2017;100:153-162.

14. Rathore K, Campbell L, Sherwood S, Nunes E. Cotton (Gossypium hirsutum L.). In: Agrobacterium Protocols. Wang K, Ed.; Springer: New York, NY, USA. 2015;pp. 11-23.

15. Wendel JF, Brubaker CL, Seelanan T. The origin and evolution of Gossypium. In: Stewart JM, Oosterhuis DM, Heitholt JJ, Mauney JR (eds) Physiology of Cotton. Springer, Dordrecht. 2010;pp 118.

16. Nicoletto C, Maucieri C, Zanin G, Vianello F, Sambo P. Vegetables quality and biotic stress. In: Plant Health Under Biotic Stress. Springer, Singapore. 2019;pp. 107-128.

17. Shafiq M, Iqbal Z, Alia I, Abbas Q, Mansoor S, Briddon RW, Amin I. Real-time quantitative PCR assay for the quantification of virus and satellites causing leaf curl disease in cotton in Pakistan. J Virol Methods. 2017;248:54-60.

18. Briddon RW, Mansoor S, Bedford ID, Pinner MS, Markham PG. Clones of cotton leaf curl geminivirus induce symptoms atypical of cotton leaf curl disease. Virus Genes. 2000;20(1):19-26. 
19. Rahman M, Rahmat Z, Mahmood A, Abdullah K, Zafar Y. Cotton germplasm of Pakistan. In: Abdurakhmonov IY, editor. World Cotton Germplasm eResources. InTech, Rijeka, Croatia. 2014.

20. Anjum ZI, Hayat K, Chalkin S, Azhar TM, Shehzad U, Ashraf F, Tariq M, Mehmood HT, Azam M. Development of cotton leaf curls virus tolerance varieties through interspecific hybridization. Afr $\mathrm{J}$ Agri Res. 2015;10(13):1612-1618.

21. Brown JK, Zerbini FM, Navas-Castillo J, Moriones E, Ramos-Sobrinho R, Silva JC, Fiallo-Olive E, Briddon RW, Hernandez-Zepeda C, Idris A, Malathi VG, Martin DP, Rivera-Bustamante R, Ueda S, Varsani A. Revision of Begomovirus taxonomy based on pairwise sequence comparisons. Arch Virol. 2015;160(6):1593-1619.

22. Manani DM, Ateka EM, Nyanjom SR, Boykin LM. Phylogenetic relationships among whiteflies in the Bemisia tabaci (Gennadius) species complex from major cassava growing areas in Kenya. Insects. 2017;8(1):25.

23. Zerbini FM, Briddon RW, Idris A, Martin DP, Moriones E, Navas-Castillo J, Rivera-Bustamante R, Roumagnac P, Varsani A. ICTV Virus Taxonomy Profile: Geminiviridae. J Gen Virol. 2017;98(2):131133.

24. Briddon RW, Mansoor S, Bedford ID, Pinner MS, Saunders K, Stanely J, Zafar Y, Malik KA, Markham PG. Identification of DNA components required for induction of cotton leaf curl disease. Virol. 2001;285(2):234-243.

25. Mansoor S, Amin I, Briddon RW (2008) Cotton Leaf Curl Disease. In: Mahy, B. W. J. \& van Regenmortel, M. H. V. (Eds): Encyclopedia of Virology. Academia Press, Oxford. 2008;pp. 563-569.

26. Cai JH, Xie K, Lin L, Qin BX, Chen BS, Meng JR, Liu YL. Cotton leaf curl Multan virus newly reported to be associated with cotton leaf curl disease in China. New Dis Rep. 2010;20:29.

27. Zhou X. Advances in understanding begomovirus satellites. Annu Rev Phytopathol. 2013;51:357381.

28. Idris AM, Shahid MS, Briddon RW, Khan AJ, Zhu JK, Brown JK. An unusual alphasatellite associated with monopartite begomoviruses attenuates symptoms and reduces betasatellite accumulation. $J$ Gene Virol. 2011;92(3):706-717.

29. Briddon RW, Markham PG. Cotton leaf curl virus disease. Virus Res. 2000;71(1):151-159.

30. Ahmad S, Noor-ul-Islam A, Mehmood F, Ashraf K, Hayat, Hanif M. Screening of cotton germplasm against cotton leaf curl virus. Pak J Bot. 2010;42(5):3327-3342.

31. Qazi J, Amin I, Mansoor S, Iqbal MJ, Briddon RW. Contribution of the satellite encoded gene $\beta C 1$ to cotton leaf curl disease symptoms. Virus Res. 2007;128(1):135-139.

32. Farooq A, Farooq J, Mahmood A, Shakeel A, Rehman KA, Batool A, Riaz M, Shahid MTH, Mehboob S. An overview of cotton leaf curl virus disease (CLCuD) a serious threat to cotton productivity. Aust $J$ Crop Sci. 2011;5(13):1823.

33. Sattar MN, Kvarnheden A, Saeed M, Briddon RW. Cotton leaf curl disease-an emerging threat to cotton production worldwide. J Gene Virol. 2013;94(4):695-710. 
34. Liu N, Xue Y, Guo Z, Li W, Tang J. Genome-wide association study identifies candidate genes for starch content regulation in maize kernels. Front Plant Sci. 2016;7:1046.

35. Abdurakhmonov IY, Abdukarimov A. Application of association mapping to understanding the genetic diversity of plant germplasm resources. Int J Plant Genom. 2008;574927. http://dx.doi.org/10.1155/2008/574927.

36. Saeed M, Wangzhen G, Tianzhen Z. Association mapping for salinity tolerance in Cotton (Gossypium hirsutum L.) germplasm from US and diverse regions of China. Aust J Crop Sci. 2014;8(3):338-346.

37. Rahman M, Khan AQ, Rahmat Z, Iqbal MA, Zafar Y. Genetics and genomics of cotton leaf curl disease, its viral causal agents and whitefly vector: A way forward to sustain cotton fiber security. Front Plant Sci. 2017;8:1157. doi: 10.3389/fpls.2017.01157.

38. Saeed M, Xianliang S, Xuezhen S, Riaz M. Leaf cuticular wax content is involved in cotton leaf curl virus disease resistance in cotton (Gossypium hirsutum L.). Spanish J Agric Res. 2018;16(4):e0705. https://doi.org/10.5424/sjar/2018164-13085

39. Saeed M, Guo WZ, Ullah I, Tabbasam N, Zafar Y, Rahman M, Zhang TZ. QTL mapping for physiology, yield and plant architecture traits in cotton (Gossypium hirsutum L.) grown under well-watered versus water-stress conditions. Electron J Biotechnol. 2011;14 (3).

40. Yuan $Y$, Zhang $H$, Wang L, Xing H, Mao L, Tao J, Wang X, Feng W, Wang Q, Wang H, Wei Z, Zhang G, Song XL, Sun XZ. Candidate quantitative trait loci and genes for fiber quality in Gossypium hirsutum L. detected using single- and multi-locus association mapping. Ind Crop Prod. 2019;134:356-389.

41. Akhtar KP, Haidar S, Khan MKR, Ahma M, Sarwar N, Murtaza MA, Aslam M. Evaluation of Gossypium species for resistance to cotton leaf curl Burewala virus. Ann Appl Biol. 2010;157(1):135-147.

42. Zhang J, Wu YT, Guo WZ, Zhang TZ. Fast screening of SSR markers in cotton with PAGE/silver staining. Cotton Sci Sin. 2000;12:267-269.

43. Pritchard JK, Stephens M, Donnelly P. Inference of population structure using multilocus genotype data. Genetics. 2000;155(2):945-959.

44. Bradbury PJ, Zhang Z, Kroon DE, Casstevens TM, Ramdoss Y, Buckler ES. TASSEL: software for association mapping of complex traits in diverse samples. Bioinformatics. 2007;23(19):2633-2635.

\section{Tables}

Table 1 List of cultivars used in this study. 


\begin{tabular}{|c|c|c|c|}
\hline Sr. NO. & Cultivar Name & Species & Origin \\
\hline 1. & CIM-1100 & Gossypium hirsutum L. & CCRI, PCCC, Multan, Pakistan \\
\hline 2. & VH-148 & Gossypium hirsutum L. & CRS, AARI, Vehari, Pakistan \\
\hline 3. & Stoneville & Gossypium hirsutum L. & USA \\
\hline 4. & SLS-1 & Gossypium hirsutum L. & CRS, PCCC, Sahiwal, Pakistan \\
\hline 5. & MS-40 & Gossypium hirsutum L. & CRS, AARI, Multan, Pakistan \\
\hline 6. & MS-39 & Gossypium hirsutum L. & CRS, AARI, Multan, Pakistan \\
\hline 7. & MNH-636 & Gossypium hirsutum L. & CRS, AARI, Multan, Pakistan \\
\hline 8. & MNH-554 & Gossypium hirsutum L. & CRS, AARI, Multan, Pakistan \\
\hline 9. & MNH-552 & Gossypium hirsutum L. & CRS, AARI, Multan, Pakistan \\
\hline 10. & LSS & Gossypium hirsutum L. & CRI, Faisalabad \\
\hline 11. & FH-901 & Gossypium hirsutum L. & CRI, AARI, Faisalabad, Pakistan \\
\hline 12. & FH-900 & Gossypium hirsutum L. & CRI, AARI, Faisalabad, Pakistan \\
\hline 13. & FH-682 & Gossypium hirsutum L. & CRI, AARI, Faisalabad, Pakistan \\
\hline 14. & FH-1000 & Gossypium hirsutum L. & CRI, AARI, Faisalabad, Pakistan \\
\hline 15. & FH-113 & Gossypium hirsutum L. & CRI, AARI, Faisalabad, Pakistan \\
\hline 16. & IR-NIAB-824 & Gossypium hirsutum L. & NIAB, Faisalabad, Pakistan \\
\hline 17. & CIM-506 & Gossypium hirsutum L. & CCRI, PCCC, Multan, Pakistan \\
\hline 18. & CIM-499 & Gossypium hirsutum L. & CCRI, PCCC, Multan, Pakistan \\
\hline 19. & CIM-496 & Gossypium hirsutum L. & CCRI, PCCC, Multan, Pakistan \\
\hline 20. & CIM-482 & Gossypium hirsutum L. & CCRI, PCCC, Multan, Pakistan \\
\hline 21. & CIM-448 & Gossypium hirsutum L. & CCRI, PCCC, Multan, Pakistan \\
\hline 22. & CIM-446 & Gossypium hirsutum L. & CCRI, PCCC, Multan, Pakistan \\
\hline 23. & CIM-109 & Gossypium hirsutum L. & CCRI, PCCC, Multan, Pakistan \\
\hline 24. & BS-1 & Gossypium hirsutum L. & $\begin{array}{l}\text { CRS, AARI, } \\
\text { Khanpur, Pakistan }\end{array}$ \\
\hline 25. & BH-118 & Gossypium hirsutum L. & CRS, Bahawalpur, Pakistan \\
\hline 26. & B-557 & Gossypium hirsutum L. & $\begin{array}{l}\text { CRI, AARI, } \\
\text { Faisalabad, Pakistan }\end{array}$ \\
\hline 27. & $4-\mathrm{F}$ & Gossypium hirsutum L. & CRI, Faisalabad \\
\hline 28. & CIM-473 & Gossypium hirsutum L. & CCRI, PCCC, Multan, Pakistan \\
\hline 29. & $268-\mathrm{F}$ & Gossypium hirsutum L. & CRSS, Jhang, Pakistan \\
\hline 30. & MNH-814 & Gossypium hirsutum L. & CRS, AARI, Multan, Pakistan \\
\hline
\end{tabular}

AARI Ayub Agricultural Research Institute; CCRI Central Cotton Research Institute; CRI Cotton Research Institute; CRS Cotton Research Station; CRSS Cotton Research Sub-station; PCCC Pakistan Central Cotton Committee 
Table 2 Mean squares of ANOVA for cotton genotypes combined data of two years of PDI and SCY.

\begin{tabular}{|l|l|l|l|}
\hline SoV/Trait & df & PDI (\%) & SCY (g) \\
\hline Blocks & 2 & $1.87 * * *$ & 2721.71 ns \\
\hline Genotype & 29 & $262.48^{* * *}$ & $8092.74^{* * *}$ \\
\hline Year & 1 & $517.45^{* * *}$ & $550229.49^{* * *}$ \\
\hline Genotype $\times$ Year & 29 & $176.78^{* * *}$ & $4272.30^{* * *}$ \\
\hline Error & 118 & 0.13 & 919.09 \\
\hline$R^{2}$ & & 0.9988 & 0.8940 \\
\hline CoV & & $3.59 \%$ & $21.29 \%$ \\
\hline
\end{tabular}

CoV Coefficient of variation [(Root MSerror) / abs (Mean Y) × 100\%]; PDI Percent disease index; $R^{2}$ SSmodel/SStotal; SCY Seed cotton yield per plant; SoV Source of variation

Table 3 Marker pairs with highly significant LD

\begin{tabular}{|c|c|c|c|c|c|c|}
\hline Locus 1 & Chr & Locus 2 & Chr & $r^{2}$ & D & $p$ Diseq \\
\hline NAU3901 & D1-Chr15 & NAU1070 & D2-Chr14 & 0.09 & 0.41 & 0 \\
\hline NAU2572 & Unknown & NAU3901 & D1-Chr15 & 0.39 & 0.77 & 0 \\
\hline NAU2477 & A4-Chr4 & NAU2162 & D4- Chr22 & 0.62 & 1 & 0.001 \\
\hline NAU1190 & A3-Chr3 & NAU453 & A11-Chr11 & 0.15 & 0.70 & 0.001 \\
\hline NAU2572 & Unknown & BNL3280 & D13-Chr18 & 0.39 & 1 & 0.001 \\
\hline NAU1218 & A6-Chr6 & NAU1102 & Unknown & 0.72 & 1 & 0.001 \\
\hline
\end{tabular}

Chr chromosome; $D \square$ disequilibrium coefficient; $L D$ linkage disequilibrium; $p D i s e q$ probability value for LD; $r^{2}$ correlation between alleles at two loci

Table 4 Marker-trait associations for PDI and SCY of cotton genotypes through GLM analysis 


\begin{tabular}{|l|c|c|c|c|c|c|}
\hline Trait & Year & Marker & Chr & $P$ Marker & $\boldsymbol{R}^{2}$ Model & $\boldsymbol{R}^{2}$ Marker \\
\hline \multirow{3}{*}{ PDI } & 2015 & BNL1421 & A13-Chr13 & 0.05 & 0.4494 & 0.2645 \\
\cline { 3 - 7 } & & BNL946 & D10-Chr20 & 0.04 & 0.3211 & 0.2399 \\
\cline { 2 - 7 } & 2016 & NAU2336 & D2-Chr14 & 0.01 & 0.2889 & 0.2691 \\
\hline \multirow{2}{*}{ SCY } & \multirow{2}{*}{2016} & NAU3100 & D9-Chr23 & 0.02 & 0.4309 & 0.1437 \\
\cline { 3 - 7 } & & NAU3860 & A12-Chr12 & 0.03 & 0.4228 & 0.1303 \\
\cline { 3 - 7 } & NAU2419 & A1-Chr1 & 0.03 & 0.4167 & 0.1241 \\
\cline { 3 - 7 } & & NAU3011 & D13-Chr18 & 0.04 & 0.4576 & 0.2359 \\
\cline { 2 - 7 } & NAU4565 & Unknown & 0.05 & 0.4038 & 0.1113 \\
\hline
\end{tabular}

Chr chromosome; PDI Percent disease index; SCY Seed cotton yield/plant; $R^{2}$ phenotypic variance explained

Table 5 Marker-trait associations for PDI and SCY of cotton genotypes through MLM analysis

\begin{tabular}{|c|c|c|c|c|c|c|c|c|}
\hline \multirow[t]{2}{*}{ Trait } & \multirow[t]{2}{*}{ Year } & \multirow[t]{2}{*}{ Locus } & \multirow[t]{2}{*}{ Chr } & \multirow[t]{2}{*}{$P$ Marker } & \multicolumn{3}{|c|}{ Variance } & \multirow[t]{2}{*}{ Heritability } \\
\hline & & & & & Genetic & Residual & Total & \\
\hline \multirow[t]{3}{*}{ PDI (\%) } & 2015 & BNL1421 & A13-Chr13 & 0.01 & 21.43 & 2.32 & 23.75 & 0.90 \\
\hline & \multirow[t]{2}{*}{2016} & BNL946 & D10-Chr20 & 0.05 & 0.03 & 3296.90 & 3296.93 & 1.00E-05 \\
\hline & & NAU2336 & D2-Chr14 & 0.01 & 8.11E-04 & 81.06 & 81.06 & 1.00E-05 \\
\hline \multirow[t]{5}{*}{ SCY } & \multirow[t]{5}{*}{2016} & NAU3100 & D9-Chr23 & 0.02 & 0.02 & 2352.86 & 2352.89 & 1.00E-05 \\
\hline & & NAU3860 & A12-Chr12 & 0.03 & 0.02 & 2306.20 & 2306.22 & 1.00E-05 \\
\hline & & NAU2419 & A1-Chr1 & 0.03 & 0.02 & 2330.89 & 2330.91 & 1.00E-05 \\
\hline & & NAU3011 & D13-Chr18 & 0.04 & 0.02 & 2397.12 & 2397.14 & $1.00 \mathrm{E}-05$ \\
\hline & & NAU4565 & Unknown & 0.05 & 0.02 & 2382.21 & 2382.23 & 1.00E-05 \\
\hline
\end{tabular}

